\title{
Educación a distancia. Primeros meses de pandemia
}

\author{
Sergio Ordóñez Velázquez
}

\section{Resumen}

Reflexiones sobre los primeros meses de pandemia ante los cambios súbitos que nos orillaron a la implementación de métodos educativos de emergencia. Comparto mi frustración, pero también mi ilusión de un cambio, mi esperanza de que ni la distancia ni la pandemia nos vencerán.

Palabras clave: educación a distancia, respuesta de emergencia, distancia, esperanza.

\section{Distance education. First months of the pandemic}

\begin{abstract}
Reflexions on the first months of the pandemic in the face of the sudden changes that led us to the implementation of emergency educational methods. I share my frustration, but also the illusion of change, my hope that neither distance nor pandemic will defeat us.
\end{abstract}

Keywords: distance education, emergency response, distance, hope. 


\section{Sergio Ordóñez Velázquez}

serchov17@gmail.com

orcid.org/0000-0001-7158-8743

Twitter: @SerchOv

Ciudad de México. Médico Cirujano y Maestrante en Educación en Ciencias de la Salud, ambas en la Facultad de Medicina de la Universidad Nacional Autónoma de México (UNAM). Profesor de asignatura en el Departamento de Integración de Ciencias Médicas FM UNAM (IBC-1, IBC-2) desde 2018. Profesor Titular de anatomía en la Facultad Mexicana de Medicina de la Universidad La Salle.

Mi forma de enseñar imita la actuación. Cuando me subía a la tarima, me subía a un escenario. Los estudiantes son el personaje principal de la historia que intento representar y hoy la clase agoniza ante un escenario vacío. Así como el actor vive de los aplausos, el docente vive de las preguntas y comentarios de la clase.

Me detengo un segundo a pensar en lo mucho que extraño pedirles a los estudiantes que guarden silencio, en las ocasiones en las que las voces de los distraídos Ilamaban mi atención y me orillaban a detener mi tren de pensamiento. Incluso extraño "pelearme" con el proyector.

En el teatro, hacer mutis es abandonar el escenario en silencio. Hoy hemos adoptado el término mutear para silenciar los micrófonos durante las sesiones en línea. En comparación con el ingreso al aula (una transición llena de vida, movimiento, comentarios, saludos), conectarse a una clase remota se siente estático, inorgánico, con un silencio que nos recuerda la falta de interacción. 
Reconozco el tono gris de mi escrito, una visión cruda de la implementación de métodos educativos de emergencia. No obstante, mi sentir es consecuencia de la frustración.

Dice Paulo Freire que "educar es un acto de amor, por lo tanto, un acto de valentía...", pero también dice Lizandro Meza: "que tristeza que me da... me da la lejanía". Posiblemente ahí se encuentre la respuesta: en entender que en el aula o a través de las diferentes plataformas es fundamental favorecer la interacción entre los estudiantes, facilitar el intercambio de ideas, que cada clase sea una oportunidad para formar comunidad. Abrir bien los ojos para identificar a aquellos que sufren de las consecuencias del aislamiento, de las cuales no estamos exentos los docentes.

La esperanza va de la mano con ser flexibles y empáticos, vivir este proceso con la completa disposición de encontrarnos con los estudiantes a la mitad del camino $y$, en algunos casos, recorrerlo por completo sin temor. A pesar de la distancia podemos mantener la cercanía, la creatividad y la firme convicción de que nadie se quede atrás.

\section{Cómo CITAR ESTE ARTículo}

* Ordóñez Velázquez, Sergio. (2021, enero-febrero). Educación a distancia. Primeros meses de pandemia. Revista Digital Universitaria (RDU), 22(1). DOI: http:// doi.org/10.22201/cuaieed.16076079e.2021.22.1.23 